\title{
Foodie escapism
}

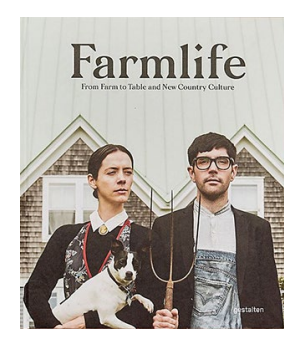

\author{
Farmlife: From Farm \\ to Table and New \\ Country Culture
}

Edited by

Robert Klanten and

Caroline Kurze

GESTALTEN: 2018.

256PP. $€ 40$

W e have probably all sat at our desks, in our labs and cubicles, within sterile buildings, and had dream-like moments thinking about escaping to the country to grow and raise living things out of the dirt with our hands. The vast majority of us will likely not quit our jobs to pursue such a dream, but Gestalten's new coffee-table book about farmers who are fiercely cultivating local food is bound to fire up the imagination (perhaps even a wood-burning fire).

While Farmlife lacks an explicit narrative - being composed entirely of vignettes of various farms, permaculture and homestead projects around the world - it does have a central, guiding core of a message: 'food empathy'. Such empathy is defined early on "as essential understanding of what food is", along with all of the various components and elements that comprise not just the food we eat but also what happens to nature when we produce, consume and dispose of our food. It envisions the whole system as a circular process in which humans should be aware of, if not involved with, each step of how the bread, vegetables and meat in our diets reaches us; not just for environmental purposes but also because it can be personally enriching to be connected on a level beyond what we experience in the grocery store. Many of the projects and farms not only aim to be self-sufficient for themselves, but also to provide for and establish a community tied to the land, attempting to counter an atomized society and discourse.

To that end the book takes us from a cooking school in Tasmania to a farming collective in Tuscany, from up-cycled greenhouses in Sweden to a floating selfsustaining complex hand-built by a couple on Vancouver Island, and from a converted parking lot in New York City to the beaches of Belgium. Recipes guide you through how to prepare butter and goat cheese, create your own sourdough starter and even make decadent desserts (preferably garnished with edible flowers from your own garden but that's not a requirement). Farmlife may be a bit twee for some, with over-emphasis on Sweden, beards and goats; many of the people featured are current or former chefs, so it may be a bit too aspirational for cubicle warriors to up and move to the middle of the country; and the text is all too brief in describing both the process and obstacles that these farms and farmers faced. But as an object, the book is exquisite in its photography showcasing lives and nature intertwined in ways that much of the developed world has forgotten or never known, to the point where you may well ditch your desk for a pair of waders, gardening gloves and the smell of fresh earth.

\section{Reviewed by Ryan Scarrow}

Published online: 5 September 2018

https://doi.org/10.1038/s41477-018-0247-1 